\title{
Study on the Accumulation and Utilization of the Employment Social Capital of Poor Medical Students
}

\author{
Xueping XU \\ Luohe Medical College, Luohe, 462000, China \\ 604141388@qq.com
}

Keywords: poor medical students; social capital; accumulation; utilization

\begin{abstract}
The labour market is not perfect enough in our country. Cultivating the consciousness of social capital and laying emphasis on effective use of social capital accumulation plays a very important role to promote the smooth employment of college students. This paper introduces social capital theory into the employment promotion of poor medical students, and puts forward suggestions of reasonable accumulation and utilizing of social capital in order to improve the employment ability of poor medical students.
\end{abstract}

\section{Introduction}

Previous studies suggest that poor medical students' manpower capital such as knowledge structure and clinical practice ability decides the employment. But it turns out that social capital also plays an important role or even overtakes human capital, and becomes the key factor to improve poor medical students' employment ability. In fact, social capital, like physical capital and human capital, can benefit its owners. During the employment process of medical underprivileged college students, social capital can help them obtain employment information and employment opportunities. The current labor market in China is not perfect enough, therefore, cultivating the consciousness of social capital and laying emphasis on effective use of social capital accumulation, plays a very important role to achieve the smooth employment and enhance the quality of employment of College students.

\section{The importance of accumulation and utilization of social capital for poor medical students}

Social capital is a popular concept in contemporary Chinese and western social sciences, it provides a new perspective for our research .Although different researchers define the concept of social capital differently from their subject category and research paradigm, its basic meaning and direction are the same. Social capital is different from physical capital and human capital, it exists in personal resources and provides convenience for the actors within the structure, including specification, trust, network form and so on[1].Simply, social capital exists in the social structure and is intangible, it brings resource from people's location in a structure of relationship , it improves the efficiency and social integration through the cooperation. It is generally believed that social capital has the following characteristics:

(1) Co-existence. Social capital is inalienable or untransferable, and the social capital that everyone has is unique. Social capital co-exists with the owner and has its using scope.

(2) Renewability. The more social capital is utilized, the greater the value. Unlike material capital, social capital will not be reduced after usage. It is reproducible and its value has increased because of the constant consumption.

(3)Transience. Social capital is produced "slowly" over time, but it can be quickly lost, and a person or a mistake will greatly waste the trust resources and social ties.

(4)Value expansion. The role of social capital is not only reflected in the productive value, but also in the sharing of benefits, which is embodied in the maintenance and promotion of the 
community of interests. Therefore, compared with other forms of capital, social capital is more social and is of value expansion.

(5)Non-imitability. Social capital is more manifested in the precipitation of the historical system, which is the code of conduct, norms and emotions that people abide by. It is a system of values and cultural resources recognized by the public or the vast majority of people. It is a humanistic environment of "people-oriented". This determines that the accumulation of social capital is difficult to form through external intervention and subjective effort. It should be noted here that the social capital accumulation discussed in the article should be carried out in the rules of market economy. As to the "power-money", "power deals" and other forms of inequality of social capital, they are not in the discussion category.

In recent years, with the serious employment situation of college students, domestic scholars have begun to study the relationship between social capital and college students' employment. American sociologist James Coleman, points out that social capital is the important resources within the college students' employment ability and the quality of life, it can mobilize social capital structure from various elements and help college graduates to achieve specific goals of employment[2]. In the process of employment, human capital is the basis, while social capital is an important factor to solve the employment problem. When the employment environment is good, human capital action is strengthened. When the employment environment is bad, social capital action is strengthened. It can be seen that social capital has important influence on college students' employment opportunity and employment choice.[3]Poor medical students are special vulnerable groups, and their poverty is not only economic poverty, but psychological poverty and skills poverty. Whether poor medical students can employ successfully not only relates to their healthy growth and the happiness of a family, but it affects the public confidence in the higher medical education investment and construction of a harmonious socialist society. Compared with other students, poor medical students not only have bad communication ability, fragile competition psychology and inferiority, but lack social capital. The relatively weak position in the process of employment makes them harder to obtain employment, longer of job-seeking, worse return on education investment. Therefore, for poor medical students, the role of social capital is not negligible, and the more high-quality social capital, the more likely to boost employment opportunities. In recent years, the phenomenon of "rich second generation" and "poor second generation" has aroused wide concern. In addition to improving their human capital, medical college students should strive to accumulate social capital. In short, accumulation and utilization of social capital can make up the defects of employment information asymmetry for poor medical students, which make them master abundant employment information, strive for more jobs and social support, reduce employment cost, and obtain employment advantage.

\section{The status of accumulation and utilization of social capital of poor medical students}

\subsection{The misunderstandings on social capital}

In China's immature labor market, valuing relationship and human culture, social capital is an important factor affecting the employment quality of college students[4]. According to the investigation, the understanding of social capital for current poor medical students is not clear, and there are still some misunderstandings.

First, part of poor medical students think that the use of social capital is the "power-power" and "power-money" trade. They not only ignore the positive role of social capital, but also show disdainful attitude to students of reasonably using social capital, even feel embarrassed and ashamed in the personal use of social capital to achieve successful employment. They don't want to use social capital to get jobs, and they don't feel ashamed to be able to gain employment through their own abilities. This kind of cognition causes some medical college students to lack the active consciousness of using social capital. 
Second, some poor medical students think that accumulating good social capital can realize smooth employment, which results the ignorance of accumulation of human capital, such as knowledge structure and clinical practice ability.

Third, some poor medical students think relationship which is advantageous to the employment is the social capital, or one-sidedly think that social capital of family is the only thing that is beneficial to obtain employment, ignoring other the positive role of social capital. This kind of cognition results in insufficient and unbalanced utilization of social capital.

\subsection{Little accumulation and unbalanced utilization of social capital}

Affected by family environment, poor medical students know little about all kinds of fashion. Combined with spending habits and values difference, lack of communication skills, and the influence of inferiority complex, it is easy to lack the common language in the process of interpersonal communication, leading to communication obstacles and narrow social circle. According to the investigation, poor medical students emphasize traditional social capital and public social capital in the process of utilizing social capital, other forms of social capital are lower utilized .Therefore, in the process of using social capital, the majority of social capital is idle and not fully utilized. In addition, poor medical students need pay economic costs to accumulate social capital, but they are short of money available for free, so the accumulation of social capital is difficult for them. They only acquire human capital through knowledge and skills.

\section{The advice of poor medical students to accumulate and utilize social capital}

Introducing social capital theory in employment ability research for medical poor college students, on the one hand, the poor college students can recognize the existence of social capital subjectively, and have a certain understanding of the influence and effect .On the other hand, the college students can choose appropriate methods to accumulate and effectively use the social capital they need to make full use of social capital in the employment.

\subsection{Eliminating misunderstandings and changing the understanding of social capital}

To obtain better employment opportunities, poor medical students must correctly understand the impact of social capital on employment. The accumulation of social capital to obtain employment opportunity is not equal to the "power and power" and "power and money" trade to achieve their own goal. They must not be confused. Accumulation and utilization of social capital should be within the rules of market economic activity. Unfair and illegal occupation of social capital should be prevented. At present, medical college students have realized the important influence of social capital on their employment, and the probability of achieving employment through social capital accumulation is relatively high. But family social capital of poor college students is very limited, it is difficult to change the status in short term. They should not complain, wait and abandon themselves. Medical college students should realize that social capital is generated in interpersonal communication, and can expand social scope and accumulate social capital by their own ability. Therefore, poor medical students should eliminate misunderstanding, change the understanding of social capital, overcome self-abased psychology, inspire potential, and firmly believe that social capital lies in not only family background. It is possible to expand the communication network and obtain social support on their own.

\subsection{Paying attention to family social capital and widening the employment channels}

The particularity of traditional Chinese culture determines that the basis of individual social capital is family social capital. The blood relationship is inheritable and most of other social relations are essentially extension of blood relationship. Family social economic status, which is composed of family and distant relatives, is the main factor that determines the social capital level of medical underprivileged students. Family socioeconomic status affects the employment intention and behavior of medical college students in different degrees. The higher the level of social capital, the higher expectation of employment and the stronger confidence of underprivileged medical 
students. And they will be able to pay less and obtain more satisfactory jobs. Poor medical students should attach importance to the family social capital, learn to love family members, and to care about family members. They can join family gatherings, take the initiative to keep in touch with relatives and communicate feelings. When relatives is in trouble, they must try their best to help them while individuals are thankful with the help of others. All of these approaches are within the framework of law and ethics to follow china's way of life. Only in this way, poor medical college students can expand employment channels and improve employment opportunities in the fierce job market.

\subsection{Using the social capital of colleges to expand the network of social relations}

College is a small society, it is rich in resources of social capital. Poor medical college students have to on their own initiative to accumulate these social capital and develop social network to increase employment opportunity. It is one of the ways of social capital accumulation to actively build a good relationship with alumni during college. The network of mutual support established between alumni can play a very important role in the future employment and work. Harvard business school, for example, compared with the education quality of the college, the network of mutual support established between the graduates has played an important role in the employment and work of graduates[5].Therefore, poor medical students should participate more in campus activities, such as Joining the students' union, club, and other associations, to break the boundaries of dormitory, department and grade. In the process, they can improve their working ability in organizing activities and establish a network of relationships, which in some ways extends the social capital of individuals.

\subsection{Participating in social practice activities to increase the stock of individual social capital}

Poor medical students actively participate in social practice activities, which can lay a solid foundation for personal ability. More importantly, practice activities multiculture and rich is also an important way to accumulation of personal social capital. Social practice activities can help poor medical students integrate professional knowledge, reduce the distance with social roles and increase the stock of individual social capital. Therefore, Medical college students should accumulate social network resources through part-time jobs, internship, and social public welfare activities. While accumulating experience, it also can make up for the deficiency of lack of social interaction and enlarge the scale of social capital. In addition, interpersonal communication requires certain material basis, but poor medical college students lack material resources, which is difficult to overcome in the accumulation of social capital. It can be recovered through diligence, homespun and other excellent qualities to win trust and cooperation. Good personality is the foundation of interpersonal attraction and trust. Poor medical students should also learn social etiquette, get along with others in good image, graceful speech, and proper manner.

\section{Summary}

In conclusion, the maintenance and expansion of employment social capital is essentially the process of competition, exchange and integration of social capital[6].The accumulation and utilization of social capital is an important way to improve the employment ability of poor medical students in the process of employment. Poor medical students should not only improve their own human capital, but accumulate social capital using various methods and improve the ability to use social capital to achieve smooth employment.

\section{Acknowledgement}

2017 Henan soft science research project "Study on the accumulation and utilization of the employment social capital of poor medical students" (172400410517). 


\section{References}

[1] Zhuang Jie. A review of "social capital" theory[J].Development of BBS,2003(1):79-80

[2] James Coleman [American]. The basis of social theory[M]. BeiJing: Social science literature publishing house, 1997.15

[3] LiBao Wu. An overview of empirical research on social capital and employment of university students[J]. Journal of Yangzhou University (high education research edition), 2011(3):64-70

[4] Jianguo Zhao, Jiaqing Wang. Study on the influence of social capital on the employment quality of college students[J] , Financial research, 2017(6):124-131

[5] MeiQun Zheng and so on. The development and utilization of college students' employment social capital. Journal of northeast normal university (philosophical social science edition),.2005(3):138-142

[6] Jianguo Zhao, Jiaqing Wang. Study on the influence of social capital on the employment quality of college students[J], Financial research,2017(6):124-131 